\title{
REBO WEKASAN MENURUT PERSPEKTIF KH. ABDUL HAMID DALAM KANZ AL-NAJĀH WA AL-SURŪR
}

\author{
Umma Farida \\ Institut Agama Islam Negeri Kudus - Indonesia \\ e-mail: ummafarida@iainkudus.ac.id
}

\begin{abstract}
This article aims to describe Rebo Wekasan and its various rituals by focusing on the thoughts of KH. Abdul Hamid Kudus have written particularly in his work Kanz al-Najāh wa al-Surūr. The data was collected through the documentation method and analyzed critically. This study found that Rebo Wekasan ritual is local wisdom combined with Islamic values. The origins of rituals carried out by some Indonesian Muslim people, especially on Java, often refer to the opinion of KH. Abdul Hamid Kudus. His thought is that Allah reveals various kinds of disasters and trials on the last Wednesday of the month of Safar, so that people were advised to perform certain rituals such as sunnah prayers, reading verses of the Qur'an, șalawat, and praying. These rituals are indeed practiced in several areas in Java with various modifications of local traditions which are manifested in the form of cultural carnivals, Quranic recitations, and selamatan (local gathering). However, his book is an inseparable from criticism, especially criticisms of sources that are considered less authoritative and critical in terms of the quality of the hadith about Rebo Wekasan.
\end{abstract}

\begin{abstract}
Abstrak: Artikel ini bertujuan untuk menggambarkan Rebo Wekasan dan berbagai ritualnya dengan berfokus pada pemikiran KH. Abdul Hamid Kudus yang ditulis secara khusus dalam karyanya Kanz al-Najāh wa al-Surūr. Data dikumpulkan melalui metode dokumentasi, dan dianalisis secara kritis. Studi ini menemukan bahwa ritual Rebo Wekasan adalah kearifan lokal yang dikombinasikan dengan nilai-nilai Islam. Asal usul ritual yang dilakukan oleh beberapa orang Muslim Indonesia, terutama di Jawa, sering merujuk pada pendapat $\mathrm{KH}$. Abdul Hamid Kudus. Menurutnya, Allah menurunkan berbagai macam bencana dan cobaan pada hari Rabu terakhir di bulan Șafar, sehingga orang disarankan untuk melakukan ritual tertentu seperti shalat sunnah, membaca ayat-ayat alQur'an, șalawat, dan shalat. Ritual ini memang dipraktekkan di beberapa daerah di Jawa dengan berbagai modifikasi tradisi lokal yang diwujudkan dalam bentuk karnaval budaya, pembacaan al-Qur'an, dan selamatan. Namun, bukunya tidak terlepas dari kritik, terutama kritik terhadap sumber yang dianggap kurang otoritatif dan kritik dalam hal kualitas hadis tentang Rebo Wekasan.
\end{abstract}

Keywords: Rebo Wekasan; KH. Abdul Hamid; local wisdom; tradition 


\section{A. Pendahuluan}

Masyarakat Indonesia, khususnya masyarakat Jawa Tengah dan Yogyakarta, memandang Rebo Wekasan sebagai hari yang dikeramatkan karena dianggap hari tersebut penuh kesialan. ${ }^{1}$ Sebagai salah satu tradisi lokal, ada perbedaan penyebutan tradisi Rebo Wekasan ini. Sebagian menyebutnya sebagai Rebo Pungkasan dan ada pula yang menyebut Rebo Kasan. Akan tetapi, penyebutan yang berbeda-beda ini tetap menunjuk pada maksud yang sama yaitu Rabu terakhir dalam bulan Șafar dalam penanggalan Hijriyah. ${ }^{2}$

Sejatinya bulan Șafar tidaklah berbeda dengan bulan-bulan lainnya. Hanya saja Rasulullah pernah menyinggung tentang bulan Șafar ini dalam hadisnya, "Tidak ada penyakit menular, tidak ada mitos, tidak ada prasangka buruk, tidak ada (keramat) bulan Șafar."3 Namun demikian, menurut KH. Abdul Hamid Kudus, bulan Șafar memiliki kekhasan tersendiri sebagaimana yang ia tulis dalam kitabnya Kanz al-Najāh wa al-Surūr. Kitab ini sering menjadi rujukan bagi sebagian masyarakat Jawa untuk menyelenggarakan ritual Rebo Wekasan ${ }^{4}$

Rebo Wekasan merupakan fenomena yang terjadi di masyarakat karena faktor akulturasi budaya Jawa dengan Islam secara intensif. Menurut Ahmad Nurozi, Islam di wilayah Jawa memiliki karakter tersendiri karena banyak prosesi ritual keagamaan yang merupakan perpaduan dari nilai-nilai Islam dengan animisme dan dinamisme. Meskipun banyak kalangan yang menganggap ritual Rebo Wekasan hanya sebagai mitos, namun juga tidak sedikit yang masih terus melestarikannya hingga sekarang. 5

Studi tentang pelaksanaan ritual dan tradisi Rebo Wekasan di berbagai daerah di Indonesia sudah banyak ditemukan. Misalnya, Ahmad Nurozi ${ }^{6}$ me-

\footnotetext{
${ }^{1}$ Mohammad Dzofir, "Agama dan Tradisi Lokal: Studi atas Pemaknaan Tradisi Rebo Wekasan di Desa Jepang, Mejobo, Kudus," Jurnal Ijtimaiya 1, no. 1 (2017): 114.

2Mundzirin Yusuf, Moch. Sodik, dan Radjasa Mu’tashim, Islam dan Budaya Lokal (Yogyakarta: Pokja Akademik UIN Sunan Kalijaga, 2005), 11.

3̇mām al-Bukhārī, Șaḥị̣ al-Bukhārī (Cairo: Dār al-Rayyān, 2001), 249.

${ }^{4}$ Dzofir, 119.

${ }^{5}$ Ahmad Nurozi, "Rebo Wekasan dalam Ranah Sosial Keagamaan di Kab. Tegal Jawa Tengah: Analisis terhadap Ritual Rebo Wekasan di Desa Sitanjung Lebaksiu," Jurnal An-Nuha, Vol. 3, no. 1 (2016): 131.

${ }^{6}$ Nurozi, "Rebo Wekasan dalam Ranah Sosial Keagamaan di Kab. Tegal Jawa Tengah: Analisis terhadap Ritual Rebo Wekasan di Desa Sitanjung Lebaksiu."
} 
lakukan penelitian tentang tradisi Rebo Wekasan dalam ranah sosial keagamaan di Desa Sitanjung, Lebaksiu, Kabupaten Tegal; Moh. Dzofir ${ }^{7}$ yang mengurai pelaksanaan Rebo Wekasan di Desa Jepang, Mejobo, Kudus; dan Rian Rahmawati, Zikri Fachrul Nurhadi, dan Novie Susanti Suseno ${ }^{8}$ yang menguak makna simbolik tradisi Rebo Kasan di Kabupaten Garut. Namun demikian, penelusuran tentang asal-usul munculnya tradisi Rebo Wekasan yang salah satunya dipengaruhi oleh pemikiran KH. Abdul Hamid Kudus tidak banyak dikaji. Oleh karena itu, artikel ini berusaha menggali pemikiran KH. Abdul Hamid Kudus tentang Rebo Wekasan atau hari Rabu terakhir bulan Șafar dalam kitabnya Kanz al-Najāḥ wa al-Surūr fi al-Ad'iyyah al-Ma'thūrah allatī Tashrah al-Ṣudūr. Metode pengumpulan data penelitian ini dilakukan melalui metode dokumentasi untuk selanjutnya dianalisis secara deskriptif-kritis.

\section{B. Tradisi Masyarakat Indonesia Menyambut Rebo Wekasan}

Amalan atau ritual yang dilakukan masyarakat Indonesia dalam menyambut Rebo Wekasan berbeda-beda dari satu daerah dengan daerah lainnya. Di antara amalan Rebo Wekasan yang dilakukan masyarakat Kudus adalah: Pertama, shalat sunnah muțlaq agar menolak bala'. Shalat ini dilaksanakan empat raka'at, baik dengan dua tahiyyat satu salam, atau dua tahiyyat dua salam. Sebagaimana shalat lainnya, shalat ini juga wajib membaca al-Fātiḥah yang dilanjutkan dengan membaca Surat al-Kauthar 17 kali, Surat al-Ikhlās 5 kali, Surat al-Falaq 1 kali dan surat al-Nās 1 kali, yang dilakukan di setiap rakaatnya. Artinya, setiap rakaat membaca seluruh surat tersebut. Seusai melaksanakan shalat, maka membaca doa tolak bala. Kedua, membaca surat Yasin. Ketika proses pembacaannya sampai pada "Salāmun qaulan min rabb al-rahìm" dibaca sebanyak 313 kali lalu dilanjutkan ayat setelahnya sampai selesai. Lalu membaca doa tolak bala. Ketiga, membuat air Salāmun. Air Salāmun adalah air yang dimasukkan di dalamnya ayat-ayat yang diawali dengan Salāmun untuk diminum agar terhindar dari malapetaka dan musibah yang akan turun dalam masa setahun. Ayat-ayat tersebut ditulis pada kertas putih kemudian dicelupkan ke dalam air dan

${ }^{7}$ Dzofir, "Agama dan Tradisi Lokal: Studi atas Pemaknaan Tradisi Rebo Wekasan di Desa Jepang, Mejobo, Kudus."

${ }^{8}$ Rian Rahmawati, Zikri Fachrul Nurhadi, dan Novie Susanti Suseno, "Makna Simbolik Tradisi Rebo Kasan," Jurnal Penelitian Komunikasi 20, no. 1 (18 Juli 2017): 61-74, https://doi.org/ 10.20422/jpkv20i1.131. 
diminum dengan niat mengharapkan berkah dan hati tetap meminta kepada Allah. Sebagian masyarakat Kudus meyakini bahwa siapapun yang meminum air tersebut maka akan diselamatkan dari berbagai malapetaka yang turun. ${ }^{9}$

Ketujuh ayat Salāmun tersebut adalah: salāmun qaulan min rabb al-rahīm, salāmun 'alā nūhin fi al-ālamīn, salāmun 'ala ibrāhīm, salāmun 'ala mūsā wa hārūn, salāmun 'àlā ilyāsīn, salāmun 'alaikum țibtum fadkhulūhā khālidīn, salāmun hiya hattā mațla'al-fajr.

Sebagian masyarakat Kudus, terutama yang tinggal di Desa Jepang, tidak membuat sendiri air Salāmun tersebut, melainkan mereka mengharap memperoleh air Salāmun dari sumur masjid-masjid tertentu yang dikeramatkan, seperti Masjid Wali al-Makmur Jepang, Mejobo, Kudus karena mereka meyakini bahwa dulu Sunan Kudus pernah menancapkan tongkatnya di masjid itu yang kemudian bekas tancapannya berubah menjadi sumur. Air Salämun ini merupakan air sumur dari masjid tersebut yang telah dibacakan al-Qur'an 30 juz dan doa-doa tertentu pada saat Rebo Wekasan. Pembagian air Salāmun biasanya dilakukan setelah pelaksanaan Kirab dengan mengelilingi desa Jepang sepanjang $5 \mathrm{~km}$ yang dimulai dan berakhir di Masjid al-Makmur. Kirab ini diikuti oleh seluruh elemen masyarakat dari pengusaha, buruh, petani, pelajar, dan lainnya. ${ }^{10}$

Senada dengan ritual Rebo Wekasan di Kudus, masyarakat Garut juga menyelenggarakan ritual Rebo Wekasan dengan melaksanakan shalat tolak bala secara individu di Masjid sebanyak dua rakaat, yang dalam setiap rakaatnya membaca Surat al-Fātihah sekali, Surat al-Kauthar 15 kali, Surat al-Ikhlāṣ 5 kali, Surat al-Falaq 1 kali, dan al-Nās 1 kali. Selanjutnya membaca doa dan șalawat secara bersama-sama.11

Sedikit berbeda dari Kudus dan Garut, ritual Rebo Wekasan yang dilakukan di Suradadi Tegal diwujudkan dalam bentuk pengajian akbar, pembacaan ayat suci al-Qur'an, Barzanji, dan Tahlilan yang dimaksudkan supaya terhindar dari

\footnotetext{
9‘Abd al-Ḥamīd, Kanz al-Najāḥ wa al-Surūr fi al-Ad'ìyyah al-Ma'thurah allatī Tashrah al-Ṣudūr (Lebanon: Dār al-Hawi, 2009), 34-35.

${ }^{10}$ Dwi Layla dan I. Awaliyah Pimay, "Warga di Kudus Rela Antre Demi Air Salamun, Konon Ini Khasiatnya," 14 November 2017, https://www.tribunnews.com/regional/2017/11/14/warga-dikudus-rela-antre-demi-air-salamun-konon-ini-khasiatnya.

${ }^{11}$ Rian Rahmawati, Zikri Fachrul Nurhadi, dan Novie Susanti Suseno, "Makna Simbolik Tradisi Rebo Kasan," Jurnal Penelitian Komunikasi 20, no. 1 (18 Juli 2017): 61-74, https://doi.org/ 10.20422/jpkv20i1.131.
} 
segala bencana dan marabahaya. ${ }^{12}$ Sedangkan di Lebaksiu Tegal diawali dengan berkunjung ke petilasan nenek moyang daerah mereka, yakni Mbah Panggung yang terletak di puncak bukit Sitanjung dengan membawa sesajen berupa kemenyan, dupa, air putih kemasan dan kembang setaman (bunga mawar, bunga cempaka putih, dan bunga melati), dan memanjatkan doa di petilasan tersebut untuk menolak kesialan dan musibah. ${ }^{13}$

Adapun upacara adat Rebo Wekasan di Wonokromo Yogyakarta dilaksanakan dengan doa bersama di depan masjid. Lazimnya, seminggu sebelum puncak acara telah diadakan keramaian, yaitu pasar malam. Upacara ini dipilih hari Rabu terakhir dari bulan Șafar yang diyakini sebagai hari pertemuan antara Sri Sultan Hamengku Buwono I dengan Kyai Faqih Usman yang berjasa menyebarluaskan agama Islam di Wonokromo Yogyakarya dan memiliki kemampuan untuk menyembuhkan penyakit. Ritual ini terus dilestarikan masyarakat Yogyakarta sebagai ungkapan syukur dan mengharap keberkahan (ngalap berkah) sekaligus menolak berbagai musibah dan penyakit. ${ }^{14}$

Ritual berupa selamatan juga banyak dilakukan masyarakat Indonesia pada saat Rebo Wekasan. Selamatan ini dilakukan dengan membagikan nasi pada tetangga atau saudara, atau membawa nasi itu ke suatu tempat seperti masjid atau mushalla untuk dinikmati bersama-sama. Mereka yang tidak mampu membuat nasi cukup membawa makanan tingan, buah-buahan atau minuman. Masyarakat Indonesia meyakini ritual selamatan ini dilakukan sebagai bentuk pendekatan diri kepada Tuhan (taqarrub) dengan mengeluarkan sedekah dengan harapan diselamatkan dari segala bentuk bencana dan musibah.15

Ritual Rebo Wekasan yang dilakukan masyarakat Indonesia tidak lepas dari keyakinan mereka yang didasarkan pada pendapat KH. Abdul Hamid Kudus bahwa Allah menurunkan ratusan ribuan jenis musibah dan kesialan pada hari Rabu terakhir bulan Safar. ${ }^{16}$

\footnotetext{
${ }^{12}$ Fatkhul Khakim, "Makna Tradisi Rebo Wekasan di Kecamatan Suradadi Tegal" (UIN Walisongo, 2014), xii.

${ }^{13}$ Nurozi, "Rebo Wekasan dalam Ranah Sosial Keagamaan di Kab. Tegal Jawa Tengah: Analisis terhadap Ritual Rebo Wekasan di Desa Sitanjung Lebaksiu."

${ }^{14}$ "Rebo Wekasan Wonokromo," gudeg.net, 2018, https://gudeg.net/direktori/333/rebowekasan-wonokromo.html. n.d.), 44.

${ }^{15}$ Abi Muhammad Azha, Hidayah Tuntunan Ibadah Sunnah 12 Bulan (t.t: Santri Creative Press,

${ }^{16}$ Dzofir, 119.
}

JURNAL THEOLOGIA — Volume 30, No. 2, December 2019 


\section{Biografi KH. Abdul Hamid Kudus}

KH. Abdul Hamid merupakan salah seorang ulama yang sangat produktif menghasilkan karya dalam berbagai disiplin ilmu. Nama lengkapnya adalah 'Abd al-Ḥamīd ibn Muhammad 'Alī Quddus ibn 'Abd al-Qādir al-Khāțib ibn 'Abdullāh ibn Mujir Quddus. Ia dilahirkan pada tahun 1277/1278 H. (1860/1861 M.) di Makkah (ada pula yang menyebutkan di Hadramaut) dan pernah singgah di kota Semarang dan Kudus, ${ }^{17}$ yang juga merupakan tempat kelahiran ayahnya yaitu KH. Muhammad 'Alī Quddus.

Pendidikan dasar pertama diterima Abdul Hamid dari ayahnya sendiri, seperti menghafal al-Qur'an, belajar tauhid, fiqh, nahwu, dan logika (Mantiq). Kemudian ia melanjutkan belajar di Masjid al-Haram. Di antara para ulama Nusantara yang bersama-sama menimba ilmu di Masjid al-Haram adalah: Jami' ibn Abd al-Rāshid al-Bugisi (1255-1361), Ahmmad al-Marzuqi ibn Ḥamīd alSawahani (1268-1355), Ja'far ibn Muhammad ibn Ja'far al-Haddad Kalianget (1279-1358), 'Abdullāh ibn Azhāri al-Falimbani (1279-1357), Muhsin ibn Muhammad al-Sirami al-Bantani (1277-1359), Hāshim Ash'ari al-Jombangi (1282-1366), dan Aḥmad al-Marzūqi ibn Aḥmad Mirsad al-Betawi (12931353).18

Semangat belajar Abdul Hamid yang tinggi menjadikannya tidak hanya puas belajar di Masjid al-Haram saja, melainkan juga melakukan perjalanan ilmiah ke Syam, Mesir, dan lainnya. Sanad keilmuan yang ia peroleh dari para gurunya yang berjumlah 17 (tujuh belas) orang dicatat dalam kitabnya, al-Mafäkhir alSaniyah. ${ }^{19}$ Namun demikian, penyebutan 17 orang gurunya dalam kitab terseut tidaklah dimaksudkan untuk pembatasan, melainkan hanya untuk menyebut para guru utamanya saja, karena sejatinya ia telah menuntut ilmu dari hampir 40 ulama yang tersebar di Mesir, Haramayn, Syam, Yaman, Beirut, Damaskus, dan Palestina. ${ }^{20}$ Di antara guru-gurunya adalah Sayyid Abū Bakr ibn Muhammad ibn 14.

${ }^{17}$ al-Ḥamīd, Kanz al-Najāḥ wa al-Surūr fi al-Ad'iyyah al-Ma'thurah allatī Tashrah al-Ṣudūr, 13-

${ }^{18}$ al-Ḥamīd.

${ }^{19}$ Arif Chasanul Muna, "Meneladani Kembali Semangat Kesantrian Syaikh Abdul Hamid Kudus," dalam Nur Said, Santri Membaca Zaman: Percikan Pemikiran Kaum Pesantren (Yogyakarta: Aswaja Pressindo, 2016), 40.

${ }^{20}$ Abdul Hamid, "al-Mafākhir al-Saniyyah fi al-Asānīd al-Aliyyah al-Qudsiyyah," Majallah Markaz Buhūth wa Dirāsāt al-Madīnah al-Munawwarah (Madinah, December ), 240. 
Mahmmud Shața, Shaikh 'Umar Shața, Shaikh Aḥmad Zaini Dahlan, Ḥabīb Ḥusain ibn Muhammad al-Habshi, Shaikh Muhammad Abū Khadir al-Dimyați, Sayyid Muhammad ibn 'Abd al-Bāqi al-Ahdal, Sayyid Zabid al-Ajall, Shaikh 'Abd al-Ḥamīd al-Daghistani, Sayyid Marjan al-Ṣaghir yang merupakan juru kunci makam Rasulullah, Shaikh Umar Hamdan, Syaikh 'Abd al-Ghani al-Hindi, Syaikh 'Abd alJalīl Buradah al-Madani, Shaikh Minnatullāh al-Misri, Shaikh Yūsuf ibn Ismāîll alNabḥani, Shaikh Aḥmad al-Rifa'i dan lainnya.

Pengembaraan intelektual Abdul Hamid ini didasarkan pada pandangannya tentang pentingnya mencari matarantai atau asal usul suatu ilmu pengetahuan, atau yang sering disebut dengan sanad. Baginya, ketersambungan matarantai periwayatan sampai Rasulullah merupakan keistimewaan milik umat Islam. Orang yang memiliki sanad keilmuan berarti ia menyandarkan ilmunya pada landasan yang kokoh dan doa-doa kebaikan akan terus mengalir. Ini dikarenakan dengan menyebutkan nama-nama para gurunya maka akan menjadi penghubung turunnya rahmat Allah dan mengikuti mereka maka akan mengantarkan kepada kebahagiaan..$^{21}$

Kelahiran Abdul Hamid di tanah Arab tidak melunturkan kecintaannya kepada kota Kudus, yang dibuktikan dengan kebanggaannya menyematkan kata 'Quddus' di belakang namanya dan nama anak-anaknya. Abdul Hamid juga pernah mengajar dalam halaqah mazhab Shafi'i di Masjid al-Haram. Di antara para muridnya yaitu Shaikh Abū Bakr ibn Muḥammad Sa'id Ba Bașil, Aḥmad Idrisi ibn Muhammad al-Ahdal, al-Qāḍi 'Abd al-Wasi' al-Wasi'i, dan Habīb 'Alī ibn 'Abd al- Raḥmān al-Ḥabshi Kwitang Jakarta. ${ }^{22}$

Tidak hanya mengajar, KH. Abdul Hamid juga produktif menulis lebih dari 21 buku dalam berbagai disiplin ilmu yang berbeda, seperti aqidah, ushul fiqh, dan sastra Arab (adab). Keseluruhan kitab ini ditulis dalam Bahasa Arab, bahkan beberapa di antaranya ada yang berbentu puisi (sya'ir).

Karya-karya KH. Abdul Hamid dapat diklafisikasikan menjadi 5 (lima) bagian, yaitu:

\footnotetext{
${ }^{21}$ Muna, "Meneladani Kembali Semangat Kesantrian Syaikh Abdul Hamid Kudus." 25.

22al-Ḥamīd, Kanz al-Najāh wa al-Surūr fi al-Ad'iyyah al-Ma'thurah allatī Tashrah al-Șudūr, 24-
} 
Pertama, karya yang disusun sebagai media pembelajaran lintas ilmu, seperti Fatḥ al-Jalīl al-Kāfi bi Mutammimah Matn al-Käfi fi 'Ilm al-Arūọ wa alQawāfi (1325 H.), Mandhūmah fi al-Adab wa al-Akhlāq al-Islāmiyah; Țalī' al-Sa'd al-Rafi' Sharh Nūr al-Badī (1321 H.), Risālah fi al-Kalām 'alā al-Basmalah wa alMabādi' al-'Ashrah (1321 H.) yang berisi tentang kajian ilmu balaghah dan arūḍ; Irshād al-Muhtadi ilā Sharḥ Kifāyat al-Mubtadi' (1309 H.) yang mengulas penjelasan Kifāyat al-Mubtadi' yang disusun ayahnya, KH. Muhammad 'Alī Quddus, dalam bidang tauhid; Lațāilif al-Ishārāt ila Sharḥ Tașil al-Ṭuruqāt li Nuẓum al-Waraqāt fi al-Ușūl al-Fiqhiyyah (1330 H.) dalam bidang ușūl fiqh; al-Anwār alSaniyyah 'alā al-Durar al-Bahiyyah (1313 H.) yang merupakan penjelasan kitab alDurar al-Bahiyyah karya Abū Bakr ibn Muhammad Shața, dalam bidang fiqh alShafi'i; Sharh al-Basmalah fi mā Yata'allaqu bihā min Fann Hadīth al-Musțalah dalam bidang ilmu hadis; Nubdhah fi al-Tașawwuf dalam bidang tasawuf.

Kedua, karya yang ditulis untuk menunjukkan keteladanan tokoh, seperti Daf'u al-Shiddah fi Tashțiiri al-Burdah (1318 H.), Majmū' Zāhir wa Tartỉbi Fākhir, Fatḥ al-Ālī al-Karìm fi Maulid Nabī al-Aẓìm, Bulūgh al-Qașd wa al-Marām fi Maulid al-Shāfi 'alaihi Af̣̣al al-Ṣalāh wa al-Salām yang semuanya berisi sanjungan kepada Rasulullah; Nayl al-Is'ād wa al-Is'äf wa al-Ma'mūl fi Māội Sayyidatinā Jaddah al-Ashrāfal-Batūl (1319 H.) yang berisi pujian terhadap Fațimah al-Zahrā, Bulūgh al-Sa'd wa al-Umniyah fi Maḍi Umm al-Mu'minin al-Mubarra'ah alSiddīqiyyah (1319 H.) yang berisi pujian terhadap Sayyidah 'Aisyah. Selain itu, ia juga menyusun beberapa buku tentang biografi ulama seperti Mawāhib al-Mu'̃̂̃ al-Munshi fi Ma'äthir al-Allāmah al-Sayyid Husain ibn Muhammad ibn Husain alHabshi (1418 H.), al-Mafākhir al-Saniyah fi al-Asānīd al-'Aliyyah al-Qudsiyyah, dan Kanz al-'Ațā fi Tarjamah al-'Allamah al-Sayyid Bakr Shața (1310 H.).

Ketiga, karya yang disusun untuk merespon problematika keagamaan yang berkembang, antara lain: al-Futūhāt al-Qudsiyyah Sharh al-Tawassulat alSamaniyah (1323 H.), al-Dhakhāir al-Qudsiyyah fi Ziyārah Khair al-Bariyyah (1321 H.); Tashțir al-Muḍarriyah fi al-Ṣalah 'ala Khair al-Bariyyah; Indhār al-Hāḍir wa alBād 'an Kitābah Ismin Mu'azzam 'ala al-Kafānī bi Mã Yațbutu Jirmuhu ka al-Madād (1322 H.), Nubdhah Tata'allaq bi al-Basmalah wa al-Mabādi' al-Ashrah min 'Ilm alTauhīd wa Ușūl al-Fiqh wa al-Fiqh wa al-Tașawwuf; al-Durrah al-Thāminah fi alMawāḍi' allati tusannu fihā al-Șalāh 'alā Șāhhib al-Sakinah, dan al-Tuhfah alMardịyah fi Jawāz Tafsìr al-Qur'ān al-'Azīm bi al-Ajamiyyah (1323 H.). 
Keempat, karya yang berisi anjuran, pesan, dan motivasi keagamaan, di antaranya al-Jawāhir al-Waḍi'iyyah fi al-Akhlāq al-Mardiyyah (1319 H.), Diyā' alShams al-Ḍāhiyyah 'ala al-Hasanāt al-Māhiyah (1323 H.), Nafahāt al-Qabūl wa alIbtihāj fi Qișsah al-Isrā' wa al-Mi'rāj (1305 H.) dan Mawāhib al-Karīm al-Mannānfi Widā'Shahr Ramaḍān.

Kelima, karya yang berisi doa-doa yang dibaca pada acara-acara tertentu, seperti Kanz al-Najāh wa al-Surūr fi al-Ad'iyyah al-Ma'thurah allatī Tashrah alȘudūr (1330 H.), dan Ithăfalf-Ikhwān bi Ad'iyah Khatm al-Qur'ān.

KH. Abdul Hamid wafat dalam usia 58 tahun di Makkah, tahun 1915 M./1334 H., dan dimakamkan di Ma'la. ${ }^{23}$

\section{Mengenal Lebih Dekat Kitab Kanz al-Najāḥ wa al-Surūr fi al-Ad'iyyah al-Ma'thurah allatī Tashrah al-Ṣudūr}

Kitab Kanz al-Najāh wa al-Surūr disusun untuk memberikan pedoman bagi umat Islam dalam berdoa. Doa merupakan salah satu hal yang dianjurkan dalam agama Islam, terlebih Allah memerintahkan umat Islam untuk berdoa, dan Allah yang akan mengabulkan doa tersebut (QS. Ghāfir: 60).

Tatkala harapan yang dipanjatkan dalam doanya belum terwujud, tidak sedikit orang-orang yang berputus asa, dan menganggap bahwa Allah Swt. tidak memenuhi janjinya dalam mengabulkan doa dan permohonan. Dalam hal ini, $\mathrm{KH}$. Abdul Hamid Kudus menjelaskan bahwa doa juga harus diiringi dengan usaha/ikhtiar, tidak hanya berdasar hawa nafsu dan keinginan saja. Selain itu, doa yang dipanjatkan menggunakan kata-kata yang jelas, tepat, dan tidak ambigu, serta tetap berprasangka baik terhadap Allah, Dzat Pengabul doa. Doa tidak hanya dibatasi pada waktu-waktu tertentu saja. KH. Abdul Hamid juga mengungkapkan bahwa doa sebaiknya dipanjatkan dengan penuh kekhusyukan dan diiringi dengan membaca al-Qur'an. ${ }^{24}$

KH. Abdul Hamid termasuk orang yang sangat berhati-hati menyikapi hadis Rasulullah. ${ }^{25}$ Ia selalu berpegang pada hadis tentang larangan berdusta secara

\footnotetext{
${ }^{23}$ al-Hamīd.

${ }^{24}$ al-Hamīd.

${ }^{25}$ al-Hamīd.
} 
sengaja atas nama beliau yang berakibat masuk ke dalam neraka, ${ }^{26}$ dan memberikan saran supaya dalam berdoa selalu menghadirkan niat hanya memanjatkan kepada Allah, bersandar kepada-Nya, tidak kepada selain-Nya.

Judul lengkap kitab ini adalah Kanz an-Najāh wa al-Surūr fi al-Ad'ìyah alMa'thürah allatī Tashrah al-Ṣudūr (Keberuntungan dan kegembiraan yang tersimpan dalam doa-doa yang melapangkan dada), yang berisi doa-doa pada harihari dan bulan-bulan tertentu selama satu tahun, seperti doa yang dibaca pada awal tahun Hijriyah, doa yang dibaca setiap hari selama sepuluh hari pertama di bulan Muharram, amalan pada bulan Asyura, Șafar, Rabi' al-Awwal, Rajab, Sha'ban, Ramadan, doa-doa yang dipanjatkan pada 10 malam terakhir dari bulan Ramadan, amalan yang dilakukan pada hari raya Idul Fitri (Shawwal) dan Dzul Hijjah, doa pada hari Arafah, dan doa akhir tahun.

Doa-doa tersebut dirujuk KH. Abdul Hamid dari beberapa kitab mu'tabar, seperti: Fatḥ al-Bārī karya Imām Ibn Hajar al-Asqalani, Musnad karya Imām Aḥmad ibn Ḥanbal, Ihyā 'Ulūm al-Dīn karya Imām al-Ghazāli, al-Mujarrabāt alKubrā karya Imām al-Dairabi, al-Adhkār karya Imam al-Nawāwi, al-Sunan alKubrā karya Imām al-Nasāi, Sunan karya al-Tirmidhi, al-Da'awāt karya alMustaghfiri, al-Nafahāat al-Nabawiyah fi al-Faḍāil al-'Ashuriyah karya Shaikh Hasan al-Hamzawi, al-Jāmi' al-Ṣaghīr karya Imam Jalāl al-Dīn al-Suyuți, dan Majma' al-Zawāid karya al-Haisami.

\section{E. Rebo Wekasan menurut KH. Abdul Hamid Kudus}

Sejatinya Islam mengajarkan bahwa setiap bulan adalah netral, dalam arti tidak mendatangkan keuntungan atau kesengsaraan tertentu. Namun demikian, tradisi dan persepsi dari umat-umat terdahulu terhadap bulan-bulan tersebut juga menjadi tak terelakkan. Kaum Arab Jahiliyah berpandangan adanya bulanbulan tertentu yang dapat mendatangkan bencana dan musibah, seperti bulan Șafar, sehingga mereka mengurungkan segala aktivitas pada bulan Șafar karena khawatir tertimpa musibah. ${ }^{27}$

Demikian pula dengan tradisi sebagian masyarakat Indonesia, khususnya masyarakat Jawa yang memandang Allah menurunkan banyak cobaan dan

\footnotetext{
${ }^{26}$ Muslim, Sahịh Muslim (Beirut: Dār al-Fikr, 2001), 21.

${ }^{27}$ Azha, Hidayah Tuntunan Ibadah Sunnah 12 Bulan.
} 
musibah pada Rabu terakhir bulan Șafar, sehingga tidak jarang mereka melakukan ritual tertentu supaya terhindar dari bencana tersebut. Ritual ini lazim disebut dengan Rebo Wekasan atau Rebo Kasan dengan merujuk pada pendapat KH. Abdul Hamid dalam kitabnya Kanz al-Najāh. ${ }^{28}$

Dalam kitab tersebut, KH. Abdul Hamid menuturkan bahwa Allah menurunkan 320 ribu bencana pada Rabu terakhir bulan Șafar, sehingga hari Rabu tersebut menjadi hari tersulit dalam setahun, sehingga disarankan untuk melakukan ritual tertentu/amalan dan memperbanyak doa pada hari tersebut. ${ }^{29}$

Di antara doa tersebut adalah:

Dengan nama Allah yang Maha Pengasih lagi Maha Penyayang. Ya Allah, limpahkanlah salawat, barakah, dan salam atas Sayyidina Muhammad hamba-Mu, nabi dan rasul-Mu, nabi yang Ummy dan keluarganya.

Ya Allah, aku berlindung kepada-Mu dari keburukan bulan ini dan dari setiap kesulitan, cobaan, dan bencana yang Engkau takdirkan di dalamnya, wahai Pencipta kehidupan, wahai Penguasa dunia dan akhirat, wahai Tuhan yang mengetahui semua peristiwa yang sudah terjadi dan yang sedang terjadi dan Tuhan yang apabila Ia menghendaki sesuatu hanya dengan cukup berkata, "Jadilah", maka sesuatu itupun akan terjadi.

Wahai Tuhanku yang Azali, wahai Tuhan yang Abadi, wahai Tuhan yang menciptakan dari permulaan, wahai Tuhan yang mengembalikan (menghidupkan)nya kembali.

Wahai Tuhan yang memiliki keagungan dan kemuliaan, wahai Tuhan pemilik Arsy yang Maha Mulia. Engkau melakukan apa saja yang Engkau kehendaki.

Ya Allah, jagalah dengan pengawasan-Mu, diriku, istriku, hartaku, anakku, agama dan duniaku yang Engkau mengujiku dan menemaninya demi kehormatan orang-orang soleh dan orang-orang baik, dengan rahmat-Mu, wahai Tuhan yang Maha Perkasa, wahai Tuhan yang Maha Pengampun, wahai Tuhan yang Maha Pemurah, wahai Tuhan yang menutupi kejelekan, dengan rahmat-Mu, wahai Tuhan yang Maha Penyayang di antara para penyayang.

Ya Allah, wahai Tuhan yang Maha Kuat, wahai Tuhan yang Maha Keras siksa-Nya, wahai Tuhan yang Maha Perkasa, tunduk kepada keperkasaanMu semua makhluk-Mu, lindungilah aku dari semua makhluk-Mu.

\footnotetext{
${ }^{28}$ Dzofir, 119.

${ }^{29}$ al-Ḥamīd, Kanz al-Najāḥ wa al-Surūr fi al-Ad'ìyyah al-Ma'thurah allatī Tashrah al-Ṣudūr, 94.
} 
Wahai Tuhan yang selalu berbuat baik, wahai Tuhan yang membuat kebagusan, wahai Tuhan yang memberi karunia, wahai Tuhan yang memberi kenikmatan, wahai Tuhan yang memuliakan, wahai Tuhan yang tiada Tuhan selain Engkau, dengan rahmat-Mu, wahai Tuhan yang Maha Penyayang di antara para penyayang. 30

KH. Abdul Hamid menyandarkan doa di atas ditemukan dari tulisan seorang yang șalih. Namun ia tidak menyebutkan secara jelas siapa yang dimaksud dengan orang șalih tersebut. Jika hal ini dianalisis dengan teori al-tahammul wa al-adā' dalam ilmu Hadis, maka perolehan KH. Abdul Hamid dari gurunya yang shalih tersebut dilakukan dengan cara wijādah, yang menempati posisi terendah dalam tingkatan al-tahammul wa al-adā'.

Al-tahammul wa al-adä' adalah tata cara penerimaan dan penyampaian hadis untuk menunjukkan bahwa apakah hadis itu benar-benar berasal dari Nabi ataukah bukan, dan untuk mengukur kualitas periwayatnya apakah dapat dipertanggung jawabkan ataukah tidak. Adapun tingkatan at-tahammul wa aladō'secara berurutan adalah: 1) Mendengar suatu hadis langsung dari gurunya (samā'), 2) Membaca hadis di hadapan gurunya (qira'ah/'arḍ), 3) perolehan ijin dari guru kepada seseorang untuk meriwayatkan hadis yang dimilikinya, baik izin itu secara lisan ataupun tertulis (ijāzah), 4) pemberian kitab hadis dari seorang guru kepada muridnya untuk diriwayatkan (munāwalah). 5) guru menuliskan sendiri atau menyuruh orang lain untuk menuliskan sebagian hadisnya guna diberikan kepada murid yang ada di hadapannya atau yang tidak hadir dengan jalan dikirimi surat melalui orang yang dipercaya untuk menyampaikannya (mukātabah). 6) guru memberitahukan kepada muridnya, bahwa kitab atau hadis yang diriwayatkannya dia terima dari seseorang (guru), dengan tanpa memberikan izin kepada muridnya untuk meriwayatkannya (i'läm). 7) periwayat hadis mewasiatkan kitab hadis yang diriwayatkannya kepada orang lain (wasiyyah). 8) seseorang memperoleh hadis orang lain dengan mempelajari kitab-kitab hadis dengan tidak melalui cara samā', ijāzah atau munāwalah. Atau dengan kata lain, seseorang dengan tidak melalui ketiga cara di atas, mendapati hadis yang ditulis oleh periwayatnya. Orang yang mendapati tulisan hadis itu dapat saja semasa atau tidak semasa dengan penulis hadis

${ }^{30}$ al-Hamīd. 
tersebut, pernah atau tidak pernah bertemu, pernah atau tidak pernah meriwayatkan hadis dari penulis dimaksud (wijādah). ${ }^{31}$

Tidak hanya doa yang dipanjatkan pada saat Rebo Wekasan tersebut, melainkan juga ada ritual-ritual tertentu yang disarankan oleh KH. Abdul Hamid pada hari Rabu tersebut, berupa shalat sunnah muțaq empat rakaat. Shalat sunnah muțlaq yang dimaksud di sini adalah shalat sunnah yang tidak dibatasi oleh waktu, sebab, dan jumlah rakaatnya. Akan, tetapi masyarakat awam sering menyebut shalat sunnah muțlaq ini sebagai shalat tolak bala. ${ }^{32} \mathrm{KH}$. Abdul Hamid menyarankan dalam melaksanakan shalat sunnah tersebut pada setiap rakaatnya membaca Surat al-Kauthar 17 kali, al-Ikhlāṣ 5 kali, al-Falaq 1 kali, dan al-Nās 1 kali setelah membaca Surat al-Fātiḥah. ${ }^{33}$

Ritual Rebo Wekasan yang disarankan KH. Abdul Hamid tidaklah mutlak. Ulama lain, Shaikh Shukur Kanji dalam kitabnya Khawājah Mughnī al-Din dan alBuni dalam kitab al-Firdaus juga menyinggung penjelasan tentang turunnya beragam bencana di hari Rabu terakhir bulan Șafar dan menyarankan untuk menunaikan shalat enam rakaat, yang dilakukan setiap dua rakaat salam. Rakaat pertama membaca al-Fātiḥah dan Ayat al-Kursi, sedangkan dalam rakaat kedua membaca Surat al-Fātiḥah dan al-Ikhlāṣ, lalu berdoa:

Ya Allah, aku mohon kepada-Mu dengan nama-nama-Mu yang terbaik dan kalimat-kalimat-Mu yang sempurna dan demi kehormatan Nabi-Mu Muhammad supaya Engkau lindungi aku dan menyelamatkanku dari bencana-Mu.

Wahai Tuhan yang menolak segala bencana, wahai Tuhan yang menyingkirkan kesusahan, wahai Tuhan yang menghilangkan kesedihan, singkirkan dariku kesusahan atau kesedihan yang ditetapkan atas diriku di tahun ini. Sesungguhnya Engkau Maha Kuasa atas segala sesuatu.

Selain menunaikan shalat dan membaca doa, KH. Abdul Hamid Kudus juga menyatakan anjuran membaca Surat Ya sin pada hari Rebo Wekasan tersebut, dan ketika sampai pada ayat Salāmun qaulan min rabb al-rahìm, maka ayat ini diulang pembacaannya sebanyak 313 kali, lalu membaca doa: ${ }^{34}$

\footnotetext{
${ }^{31}$ Umma Farida, Metode Penelitian Hadis (Kudus: Nora Media, 2010), 12-18.

${ }^{32}$ Rahmawati, Nurhadi, dan Suseno, "Makna Simbolik Tradisi Rebo Kasan."

${ }^{33}$ al-Hamīd, Kanz al-Najāḥ wa al-Surūr fi al-Ad'ìyyah al-Ma'thurah allatī Tashrah al-Ṣudūr, 97.

${ }^{34}$ al-Hamīd.
}

JURNAL THEOLOGIA — Volume 30, No. 2, December 2019 
Ya Allah, limpahkanlah șalawat dan rahmat atas Sayyidina Muhammad dengan rahmat yang menyelamatkan kami dari semua bahaya dan gangguan dan memenuhi hajat-hajat kami, membersihkan kami dari seluruh dosa, mengangkat kami derajat tertinggi, menyampaikan kami ke tujuan terjauh berupa seluruh kebaikan semasa hidup dan sesudah mati.

Jika ditelusuri bacaan surat al-Fātiḥah, Ayat al-Kursi, al-Kauthar, al-Ikhlās, alFalaq, dan al-Nās yang disarankan untuk dibaca dalam shalat sunnah muṭlaq pada saat Rebo Wekasan memang memiliki korelasi dengan keutamaan surat-surat tersebut sebagaimana dinyatakan dalam sabda Rasulullah, antara lain:

Dari Ibn Abbas berkata bahwasanya Malaikat Jibril memberitahukan kepada Nabi "Sampaikanlah kabar gembira dengan dua cahaya yang tidak diberikan kepada seorang Nabi pun sebelummu, yaitu Surat al-Fätihah dan akhir Surat al-Baqarah yang apabila dibaca ayatnya pasti akan diberikan apa yang diinginkannya."35

Dari Abdul Malik ibn Umair berkata, Rasulullah bersabda, "Surat al-Fätị̆ah adalah obat dari seluruh penyakit."36

Dari Mu'adz ibn Abdillah ibn Khubaib dari ayahnya berkata, "Kami pernah keluar pada suatu malam yang hujan dan sangat gelap lalu kami meminta Rasulullah untuk mendoakan keselamatan kami, maka Rasulullah bersabda, "Bacalah." Lalu kami bertanya kepada Rasulullah, "Apa yang kami baca?" Rasulullah menjawab, "Qul Huwallāhu Ahad dan Mu'awwidhatain ketika waktu sore dan pagi tiga kali niscaya cukup bagimu dari segala sesuatu."37

Dari Anas ibn Malik dari Nabi bersabda, "Barangsiapa membaca Qul Huwallāhu Ahad setiap hari 200.000 kali maka akan dihapus dosanya lima puluh tahun kecuali jika ia memiliki hutang."38

Dari Muhajir al-Sha'igh bahwa Nabi mendengar seorang sahabat membaca Qul Yã Ayyuhal Kāfirūn maka Nabi bersabda, "Surat ini membebaskan dari syirik", dan ketika beliau mendengarkan sahabat lain membaca Qul Huwallāhu Ahad maka Nabi bersabda, "Adapun surat ini (menjadi wasilah) diampuni dosanya."39

\footnotetext{
${ }^{35}$ al-Nasā'i, Sunan al-Nasā'i (Cairo: Dār al-Hadīth, 2001), 1: 903.

${ }^{36}$ al-Darimī, Sunan al-Darimī (Cairo: Dār al-Hadīth, 2006), 3: 433.

${ }^{37} A b u \overline{~ D a ̄ w u ̄ d, ~ S u n a n ~ A b u ̄ ~ D a ̄ w u ̄ d ~(B e i r u t: ~ D a ̄ r ~ a l-J a y l, ~ 2001), ~ 4: ~} 413$.

38al-Tirmidhi, Sunan al-Tirmidhi (Beirut: Dār al-Fikr, 2007), 823.

${ }^{39}$ Aḥmad ibn Ḥanbal, Musnad Ahmad (Aleppo: Maktabah al-Bāb al-Halabi, 2004), 6022.
} 
Adapun Ayat al-Kursi yang disarankan untuk dibaca dalam ritual shalat hari Rebo Wekasan penulis temukan dalam Sunan al-Darimi yang disebutkan dalam riwayat Abdullah ibn Mas'ud bahwa ia berkata, "Barangsiapa yang membaca empat ayat dari awal Surat al-Baqarah, Ayat al-Kursi, dua ayat setelah ayat alKursi, tiga ayat terakhir Surat al-Baqarah maka ia dan keluarganya tidak akan didekati setan dan tidak ada sesuatu yang buruk yang menimpanya." ${ }^{40}$ Demikian pula hadis marfü' yang diriwayatkan oleh Abu Hurairah dari Rasulullah bersabda, "Barang siapa membaca Ayat al-Kursi di pagi hari maka ia tidak akan mendapati hal-hal yang tidak ia sukai sampai sore hari, dan barangsiapa yang membacanya di sore hari maka ia tidak akan menjumpai hal-hal yang dibencinya itu hingga pagi esok hari." 41

Adapun pembuatan air Salāmun pada saat Rebo Wekasan sebagaimana banyak diyakini masyarakat Kudus juga ditemukan korelasinya dengan pendapat KH. Abdul Hamid dalam kitabnya Kanz al-Najāh wa al-Surūr ini. Dalam hal ini, KH. Abdul Hamid mendasarkan kepada muallif kitab Na'tal-Bidāyātyang dan amalan dari para gurunya sebelumnya meskipun $\mathrm{KH}$. Abdul Hamid tidak menyebut secara spesifik nama-nama para gurunya tersebut. ${ }^{42}$

Jika ditelusuri lebih lanjut KH. Abdul Hamid Kudus bukan satu-satunya ulama yang berbicara tentang Rebo Wekasan sekaligus doa dan ritual yang dilakukan pada hari Rabu tersebut. Imam al-Baghawi dalam kitab Tafsirnya, Ma'âlim al-Tanzil juga mengulas tentang kejadian nahas yang terus-menerus yang terjadi pada hari Rabu terakhir setiap bulan termasuk bulan Șafar ketika menafsirkan QS. al-Qamar: 18-20. Kesialan dan peristiwa naas tersebut luar biasa dahsyatnya dan tidak ada seorang pun yang bisa menghindarinya. ${ }^{43}$

Penjelasan al-Baghawi di atas, menurut penulis, sejatinya hanya spesifik terkait dengan kaum 'Ad yang mendustakan ajaran Allah, sehingga Allah murka dan menurunkan berbagai macam siksa dan musibah terhadap mereka, tidak bersifat general bagi setiap mu'min yang mentaati ajaran-ajaran-Nya.

\footnotetext{
${ }^{40}$ al-Darimì.

${ }^{41}$ al-Darimī. 100.

42al-Ḥamīd, Kanz al-Najāḥ wa al-Surūr fi al-Ad'iyyah al-Ma'thurah allatī Tashrah al-Șudūr, 99-

${ }^{43}$ Abū Muhammad al-Ḥusain ibn Mas'ūd al-Baghawi, Ma'ālim al-Tanzīl (Riyadh: Dār Thaibah, 2007), 430.
}

JURNAL THEOLOGIA — Volume 30, No. 2, December 2019 
Senada dengan al-Baghawi, Imam al-Munawi dalam Fayḍ al-Qadìr menyinggung adanya hari Rabu yang dianggap sebagai hari naas, sial, dan sumber bencana yang terjadi secara terus-menerus. ${ }^{44}$ Demikian pula dengan Imam alTabrani dalam al-Mu'jam al-Awsaț-nya meriwayatkan hadis yang berbunyi: ${ }^{45}$

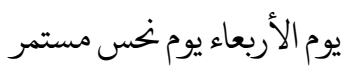

Hari Rabu adalah hari naas yang terus menerus.

Hadis di atas diriwayatkan oleh Muhammad ibn 'Umar ibn Manshur alBajali, dari Qutaibah ibn Sa'id, dari Ibrāhīm ibn Abī Hayyah, dari Ja'far ibn Muhammad, dari ayahnya, dari Jabir, dari Rasulullah. Namun demikian, kualitas

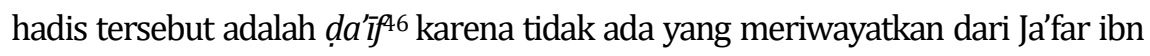
Muhammad kecuali Ibrāhīm ibn Abī Ḥayyah yang dikenal sebagai munkar alhadith, yakni periwayat yang hadisnya diingkari karena bertentangan dengan hadis lain yang lebih kuat. ${ }^{47}$

\section{F. Ritual Rebo Wekasan: Kearifan Lokal vis a vis Ajaran Islam}

Ritual Rebo Wekasan sebagaimana yang dinarasikan KH. Abdul Hamid Kudus dapat dikategorikan sebagai kearifan lokal yang tidak bertentangan dengan nilai-nilai Islam. Meskipun ditemukan beberapa kelemahan mendasar terkait sumbernya, namun ritual yang dilakukan pada hari Rebo Wekasan tersebut bernafaskan ajaran Islam, seperti: Shalat sunnah, doa, membaca tujuh ayat al-Qur'an yang mengandung lafal keselamatan (salāmun), dan upacara selamatan.

Implementasi ajaran Islam di Indonesia cenderung lebih akomodatif, penuh keramahan dan toleransi. Islam sebagai ajaran yang normatif berasal dari Tuhan diakomodasikan ke dalam kebudayaan yang berasal dari manusia dengan tetap mempertahankan identitasnya masing-masing, tidak saling menafikan, melainkan berusaha mencari titik temu antara agama dan budaya. ${ }^{48}$

\footnotetext{
44al-Munāwī, Fayḍ al-Qadīr (Cairo: Maktabah at-Tawfiqiyyah, 2011), 64.

45al-Ṭabrānī, Mu'jam al-Awsāț. (Aleppo: Maktabah Isa al-Bab al-Halabi, 2011), 308.

${ }^{46}$ al-Ṭabrānī, Mu'jam al-Awsāṭ.

${ }^{47}$ Shamsuddin al-Dhahabi, Mīzān al-I'tidāl fi Naqd al-Rijāl (Beirut: Dar al-Ma'rifah, 2008), 79. 2001).

${ }^{48}$ Abdurrahman Wahid, Pergulatan Negara, Agama, dan Kebudayaan (Depok: Desantara,
} 
Perpaduan ajaran Islam dan tradisi lokal, ${ }^{49}$ salah satunya mewujud dalam bentuk ritual Rebo Wekasan sebagaimana yang berlangsung di beberapa daerah di Indonesia khususnya di Jawa mengambil inspirasi dari semangat yang diajarkan Walisongo yang sangat toleran dan akomodatif terhadap budaya dan tradisi setempat selama proses dakwahnya di tanah Jawa sekitar abad 15-16 M.50 Mereka telah mengadopsi kebudayaan lokal secara selektif, sistem sosial, kesenian dan pemerintahan yang relevan, termasuk adat istiadat, dan mengembangkannya dalam tradisi Islam. Ini dikarenakan mengisi nilai Islam ke dalam struktur budaya yang ada jauh lebih efektif daripada mengganti budaya itu sendiri. 51

Ritual kirab, pengajian, ziarah, kubur, dan selamatan yang dilakukan masyarakat ketika Rebo Wekasan merupakan kearifan lokal karena selama proses ritual itu berlangsung juga tidak lepas dari bacaan ayat al-Qur'an dan doa. Ritual ini mengakomodir berbagai tradisi lokal dan memasukkan nilai-nilai Islam di dalamnya. Ini dikarenakan dalam sejarahnya, proses islamisasi di Jawa memang tidak bisa dipisahkan dari tradisi dan budaya lokal.52

Namun demikian, Rebo Wekasan dengan berbagai ritual ini juga tidak lepas dari kritik. Pertama, kritik sumber yang dirujuk oleh KH. Abdul Hamid dalam bukunya Kanz al-Najāḥ wa al-Surūr yang dinilai kurang otoritatif karena penyandaran sumbernya yang terkesan mubham bahkan majhül karena tidak adanya penyebutan identitas asli tokoh/sumber yang dirujuk. Dalam menguraikan tentang Rebo Wekasan dalam bukunya tersebut, KH. Abdul Hamid tidak jarang mencukupkan menyandarkan pendapatnya kepada para ulama yang shalih atau wali tanpa penjelasan spesifik identitas mereka masing-masing.

Kedua, kritik terhadap kelemahan kualitas hadis tentang turunnya 320.000 macam bencana dan kesialan pada Rabu terakhir bulan Șafar yang kemudian dikenal masyarakat Indonesia khususnya masyarakat Jawa sebagai Rebo

\footnotetext{
${ }^{49}$ Abdurrohman Kasdi, "Islamic Dialectics and Culture in Establishing Islam Nusantara Paradigm (Variety Model of Islam Nusantara for Indonesia)," Jurnal Addin 12, no. 2 (2018): 303-4.

${ }^{50}$ Abdurrohman Kasdi, "The Role of Walisongo in Developing Islam Nusantara Civilization," Jurnal Addin 11, no. 1 (2017): 10-15.

${ }^{51}$ Abdul Mun'im DZ, "Mempertahankan Keragaman Budaya," Jurnal Tashwirul Afkar 14 (2003): 4.

${ }^{52}$ Umma Farida, "Islam Pribumi dan Islam Puritan: Ikhtiar Menemukan Wajah Islam Indonesia Berdasar Proses Dialektika Pemeluknya dengan Tradisi Lokal," Jurnal Fikrah 3, no. 1 (2015): 145.
} 
Wekasan. Akan tetapi, KH. Abdul Hamid tampaknya sudah menyadari kelemahan kualitas hadis tersebut, terlebih jika dikomparasikan dengan hadis Șahịh yang menyatakan tidak adanya kesialan dalam bulan-bulan tertentu, termasuk bulan Șafar. Hadis ini berbunyi:

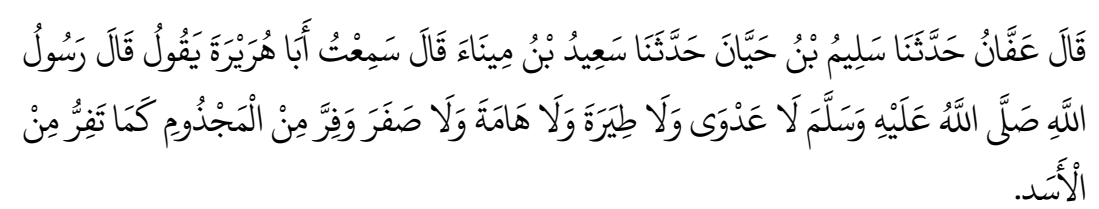

Affan berkata, Salim ibn Hayyan menyampaikan kepada kami, Sa'id ibn Mina menyampaikan kepada kami, saya mendengar Abu Hurairah berkata bahwa Rasulullah bersabda, "Tidak ada penyakit menular, tidak pula ramalan sial, tidak pula burung hantu (penanda sial) dan juga tidak ada kesialan pada bulan Șafar. Menghindarlah dari penyakit kusta sebagaimana engkau menghindari singa." 53

Hadis di atas bermaksud meluruskan keyakinan masyarakat Jahiliyah yang mempercayai adanya penularan penyakit dengan sendirinya, kesialan, mitos dan sebagainya. Sementara Islam mengajarkan bahwa segala sesuatu itu terjadi karena ketentuan atau takdir Allah. Adapun penularan hanyalah salah satu sarana berjalannya takdir Tuhan tersebut. Manusia juga tetap diwajibkan untuk ikhtiar dan berusaha agar terhindar dari segala bencana.

Namun dalam kesempatan lain, Rasulullah juga pernah bersabda, "Janganlah unta yang sakit dicampurkan pada unta yang sehat".54 "Larilah kamu dari orang yang berpenyakit lepra seperti engkau lari dari singa." 55 "Jika kalian mendengar tentang tentang berjangkitnya penyakit sampai di suatu negeri, maka janganlah kalian memasukinya. ${ }^{56}$

KH. Abdul Hamid menjelaskan bahwa ketiga hadis di atas seakan menunjukkan bahwa penularan penyakit itu bisa terjadi, maka Rasulullah memerintahkan untuk menjauhi sebab-sebab yang bisa menimbulkan penularan penyakit itu jika sebelumnya dalam kondisi sehat. Maka sebagaimana manusia

\footnotetext{
${ }^{53}$ al-Bukhāri, Șaḥīh al-Bukhāri, 476.

54al-Bukhāri.

${ }^{55}$ al-Bukhāri.

${ }^{56}$ al-Bukhāri.
} 
dilarang menjatuhkan dirinya di dalam air atau api atau masuk di bawah bangunan yang roboh dan semacamnya yang biasanya dapat menimbulkan bencana dan kebinasaan, demikian halnya mendekati penyakit lepra dan mendatangi negeri yang dilanda wabah penyakit. Ini dikarenakan semua itu merupakan sebab-sebab penyakit dan marabahaya, sedangkan Allah adalah pencipta sebab-sebab dan akibatnya tiada yang menciptakan dan mentakdirkan selain Allah. ${ }^{57}$ Bahkan Abu Dawud pernah meriwayatkan dalam kitab Marāsilnya bahwa Rasulullah melewati sebuah dinding yang miring, maka beliau berjalan cepat dan berkata, "Aku takut kematian mendadak."58

Lebih lanjut, KH. Abdul Hamid menuturkan adanya hadis lain yang menunjukkan bahwa Rasulullah pernah makan satu meja dengan orang yang berpenyakit lepra. Itu disebabkan kondisi Rasulullah yang lebih kuat dari umatnya, sehingga tidak dikhawatirkan padanya penyakit menular seperti yang dikhawatirkan pada orang lain. Dengan demikian, penularan penyakit yang disangkal adalah penularan karena karakter penyakitnya sendiri dan perintah agar menghindar darinya adalah karena Allah memberlakukan kebiasaan terjadi penularan ketika bercampur dengan yang lain atau supaya orang yang bercampur itu tidak bertepatan dengan takdir sehingga ia mengira itu adalah penyakit menular. ${ }^{59}$

Adapun maksud dari statemen "wa lā șafara" (tidak ada kesialan di bulan Șafar) adalah untuk menyanggah perilaku masyarakat Arab Jahiliyah yang mengundurkan bulan Muharram hingga Șafar dan menjadikan Șafar sebagai bulan Haram. KH. Abdul Hamid menguraikan bahwa masyarakat Arab Jahiliyah menganalogkan Șafar seperti seekor ular yang kelaparan dan siap menggigit manusia. Sehingga mereka menganggap banyak bencana dan cobaan dalam bulan Șafar tersebut.60

Terkait hari Rabu terakhir setiap bulan, termasuk Rabu terakhir bulan Șafar, yang dianggap mendatangkan kesialan itu jalur periwayatannya buruk dan tidak kuat.61 Oleh karena itu, banyak ulama seperti Imam al-Sakhawi-sebagaimana

6.

57al-Ḥamīd, Kanz al-Najāḥ wa al-Surūr fí al-Ad'iyyah al-Ma'thurah allatī Tashrah al-Ṣudūr, 101-

${ }^{58} \mathrm{Abū}$ Dāwūd, Mārāsīl (Cairo: Dār al-Hadīth, 2010), 472.

${ }^{59}$ al-Ḥamīd, Kanz al-Najāh wa al-Surūr fi al-Ad'ìyah al-Ma'thurah allatī Tashrah al-Șudūr, 108.

${ }^{60}$ al-Ḥamīd, Kanz al-Najāh wa al-Surūrfíal-Ad'iyyah al-Ma'thurah allatī Tashrah al-Ṣudūr.

${ }^{61}$ al-Sakhawi, Al-Maqāșid Al-Hasanah (Beirut: Dar al-Fikr, 2009), 943.

JURNAL THEOLOGIA — Volume 30, No. 2, December 2019 
dikutip KH. Abdul Hamid-yang menempuh metode kompromi (jam') dalam memahami hadis tersebut. Yakni, bahwa kesialan di hari Rabu terakhir setiap bulan, termasuk yang diyakini masyarakat Jawa sebagai Rebo Wekasan itu hanya berlaku bagi orang yang meyakininya. Namun, bagi yang meyakini bahwa tidak ada yang bisa memberi manfaat dan menimbulkan bahaya kecuali Allah, maka tidak ada kesialan yang menimpanya. ${ }^{62}$ Ini dikarenakan ada hadis yang diriwayatkan oleh al-Baihaqi bahwa dikabulkannya doa pada hari Rabu setelah matahari tergelincir.63 Selain itu, juga terdapat riwayat yang menyebutkan aktifitas yang dimulai pada hari Rabu maka akan sempurna, termasuk juga menanam pohon pada hari Rabu maka pohon-pohon itu akan menghasilkan buah. ${ }^{64}$ Bahkan, pada hari Rabu pula Allah menciptakan cahaya (nür), ${ }^{65}$ dan ilmu pengetahuan serta kebaikan merupakan pancaran dari cahaya.

\section{G. Kesimpulan}

Rebo Wekasan merupakan fenomena yang terjadi di masyarakat karena faktor akulturasi budaya Jawa dengan Islam secara intensif. Ritual yang dilakukan masyarakat Indonesia dalam menyambut Rebo Wekasan berbeda-beda dari satu daerah dengan daerah lainnya, seperti melakukan shalat sunnah, membaca ayat suci al-Qur'an, memanjatkan doa, membuat air Salāmun, menyelenggarakan pengajian akbar dan selamatan, bahkan kirab budaya.

Ritual Rebo Wekasan yang dilakukan masyarakat Indonesia tidak lepas dari keyakinan mereka yang didasarkan pada pendapat KH. Abdul Hamid Kudus dalam kitabnya Kanz al-Najāh wa al-Surūr bahwa Allah menurunkan ratusan ribuan jenis musibah dan kesialan pada hari Rabu terakhir bulan Șafar. Oleh karena itu, KH. Abdul Hamid menyarankan untuk melakukan ritual-ritual tertentu seperti shalat sunnah, membaca ayat-ayat al-Qur'an, șalawat, dan doa tolak bala, meskipun riwayat hadis yang dirujuknya tidak lepas dari kelemahan dan jalur periwayatan yang buruk. Namun demikian, hal ini tampaknya juga telah disadari oleh KH. Abdul Hamid sehingga ia mengiringi penjelasan tentang Rebo Wekasan yang penuh dengan bencana dan musibah, dengan penjelasan

\footnotetext{
62al-Hamīd, Kanz al-Najāḥ wa al-Surūrfí al-Ad'ìyyah al-Ma'thurah allatī Tashrah al-Ṣudūr, 121.

${ }^{63}$ al-Baihaqi, Shu'ab al-Īmān (Beirut: Dar al-Fikr, 2012), 3591.

${ }^{64}$ al-Dailami, Sunan (Aleppo: Maktabah Isa al-Bāb al-Halabi, 2010), 5479.

65al-Bukhari, Șahịh, 4997.
} 
pembanding yang menegaskan tidak adanya kesialan terkait hari Rabu dan bulan Șafar. Di sini terlihat sikap moderat KH. Abdul Hamid yang memberikan pilihan kepada masyarakat pembaca kitabnya apabila meyakini adanya beragam kesialan dan musibah di Rabu terakhir bulan Șafar maka disarankan untuk melakukan berbagai amalan untuk membentengi diri mereka. Sebaliknya, bagi yang tidak meyakininya maka tidak perlu melakukan ritual tersebut.]

\section{DAFTAR PUSTAKA}

Azha, Abi Muhammad. Hidayah Tuntunan Ibadah Sunnah 12 Bulan. t.t: Santri Creative Press, n.d.

al-Baghawi, Abū Muhammad al-Husain ibn Mas'ūd. Ma'âlim al-Tanzīl. 7 ed. Riyadh: Dār Thaibah, 2007.

al-Baihaqi. Shu'ab al-Īmān. Beirut: Dār al-Fikr, 2012.

al-Bukhāri, Imām. Shahih al-Bukhāri. Cairo: Dār al-Rayyan, 2001.

al-Dhahabi, Shamsuddin. Mīzān al-I'tidāl fi Naqd al-Rijāl. Beirut: Dār al-Ma'rifah, 2008.

al-Dailami. Sunan al-Dailami. Aleppo: Maktabah Isa al-Bab al-Halabi, 2010.

al-Darimi. Sunan al-Darimi. III. Cairo: Dār al-Hadīth, 2006.

Dāwūd, Abu. Mārāsīl. Cairo: Dār al-Hadīth, 2010.

. Sunan Abū Dāwūd. IV. Beirut: Dār al-Jayl, 2001.

Dzofir, Mohammad. "Agama dan Tradisi Lokal: Studi atas Pemaknaan Tradisi Rebo Wekasan di Desa Jepang, Mejobo, Kudus." Jurnal ljtimaiya 1, no. 1 (2017): 112-28.

Farida, Umma. "Islam Pribumi dan Islam Puritan: Ikhtiar Menemukan Wajah Islam Indonesia Berdasar Proses Dialektika Pemeluknya dengan Tradisi Lokal." Jurnal Fikrah 3, no. 1 (2015): 141-56.

___. Metode Penelitian Hadis. Kudus: Nora Media, 2010.

al-Ḥamīd, 'Abd. Kanz al-Najāh wa al-Surūr fi al-Ad'iyyah al-Ma'thurah allatī Tashrah al-Ṣudūr. Lebanon: Dār al-Hawi, 2009. 
___. "al-Mafākhir al-Saniyyah fi al-Asānīd al-Aliyyah al-Qudsiyyah." Majallah Markaz Buhūth wa Dirāsāt al-Madīnah al-Munawwarah. Madinah, Desember.

Ibn Ḥanbal, Aḥmad,. Musnad. Aleppo: Maktabah al-Bab al-Halabi, 2004.

Kasdi, Abdurrohman. "Islamic Dialectics and Culture in Establishing Islam Nusantara Paradigm (Variety Model of Islam Nusantara for Indonesia)." Jurnal Addin 12, no. 2 (2018): 299-324.

__ . "The Role of Walisongo in Developing Islam Nusantara Civilization." Jurnal Addin 11, no. 1(2017): 1-26.

Khakim, Fatkhul. "Makna Tradisi Rebo Wekasan di Kecamatan Suradadi Tegal." UIN Walisongo, 2014.

Layla, Dwi, dan I. Awaliyah Pimay. "Warga di Kudus Rela Antre Demi Air Salāmun, Konon Ini Khasiatnya," 14 November 2017. https://www.tribunnews. com/regional/2017/11/14/warga-di-kudus-rela-antre-demi-airSalāmun-konon-ini-khasiatnya.

al-Munāwī. Fayḍ al-Qadìr. 1 ed. Cairo: Maktabah at-Tawfiqiyyah, 2011.

Mun'im DZ, Abdul. "Mempertahankan Keragaman Budaya." Jurnal Tashwirul Afkar 14 (2003): 2-8.

Muna, Arif Chasanul. "Meneladani Kembali Semangat Kesantrian Syaikh Abdul Hamid Kudus." dalam Santri Membaca Zaman: Percikan Pemikiran Kaum Pesantren, diedit oleh Nur Said. Yogyakarta: Aswaja Pressindo, 2016.

Muslim. Shahih Muslim. Beirut: Dār al-Fikr, 2001.

al-Nasā'i. Sunan. I. Cairo: Dar al-Hadits, 2001.

Nurozi, Ahmad. "Rebo Wekasan dalam Ranah Sosial Keagamaan di Kab. Tegal Jawa Tengah: Analisis terhadap Ritual Rebo Wekasan di Desa Sitanjung Lebaksiu." Jurnal an-Nuha 3, no. 1 (2016): 125-36.

Rahmawati, Rian, Zikri Fachrul Nurhadi, dan Novie Susanti Suseno. "Makna Simbolik Tradisi Rebo Kasan." Jurnal Penelitian Komunikasi 20, no. 1 (18 Juli 2017): 61-74.https://doi.org/10.20422/jpk.v20i1.131.

"Rebo Wekasan Wonokromo." gudeg.net, 2018. https://gudeg.net/direktori/ 333/rebo-wekasan-wonokromo.html.

al-Sakhawi. al-Maqāṣid al-Hasanah. Beirut: Dar al-Fikr, 2009. 
al-Tirmidhi. Sunan al-Tirmidhi. 2 ed. Beirut: Dār al-Fikr, 2007.

al-Ṭabrānī. Mu'jam al-Awsāț. 2 ed. Aleppo: Maktabah Isa al-Bāb al-Halabi, 2011.

Wahid, Abdurrahman. Pergulatan Negara, Agama, dan Kebudayaan. Depok: Desantara, 2001.

Yusuf, Mundzirin, Moch. Sodik, dan Radjasa Mu'tashim. Islam dan Budaya Lokal. Yogyakarta: Pokja Akademik UIN Sunan Kalijaga, 2005. 
